\title{
The Role of Sleep in Accelerated Cognitive Aging in Bipolar Disorder
}

\author{
Christopher N. Kaufmann ${ }^{1}$ and Lisa T. Eyler ${ }^{2}$ \\ 'Division of Geriatrics and Gerontology, Department of Medicine, University of California San Diego, La Jolla, CA, USA \\ ${ }^{2}$ Department of Psychiatry, University of California San Diego, La Jolla, CA, USA
}

Bipolar disorder (BD) is thought to be associated with premature cognitive aging, but there has been relatively little research examining the role of sleep quality within this relationship. There is ample evidence for a link between sleep disturbance and cognitive decline in the general population as recent studies show this relationship longitudinally. However, there is a need to examine whether sleep disturbance in BD is associated with cognitive outcomes, and the ways in which sleep may impact premature cognitive aging. We first review the literature about early cognitive decline in $\mathrm{BD}$, and the role disturbed sleep may play in this association. Second, we provide suggestions on future research to examine the role of sleep in cognitive aging in $\mathrm{BD}$ and identify the key areas needing further research with the purpose of determining ways to improve the cognitive health and overall functioning of those with BD.

Key Words: Bipolar disorder; Sleep; Dementia; Cognitive aging

Received: March 14, 2019 Accepted: April 30, 2019

Corresponding author: Christopher N. Kaufmann, PhD, MHS, Division of Geriatrics and Gerontology, Department of Medicine, University of California San Diego School of Medicine, 9500 Gilman Drive, \#0665, La Jolla, CA 92039, USA.

Tel: 1-858-246-3135, Fax: 1-858-822-6151, E-mail: cnkaufmann@ucsd.edu

@ This is an Open Access article distributed under the terms of the Creative Commons Attribution Non-Commercial License (https://creativecommons.org/licenses/by$\mathrm{nc/4.0)}$ which permits unrestricted non-commercial use, distribution, and reproduction in any medium, provided the original work is properly cited.

Evidence suggests that accelerated or premature aging occurs in bipolar disorder (BD). Those with BD die younger, develop aging related diseases earlier, and exhibit general declines in functioning and levels of independence faster than otherwise healthy individuals [1,2]. One domain of aging-cognitive functioninghas received interest in recent years. There is well-established evidence that $\mathrm{BD}$ patients exhibit more cognitive deficits than comparable healthy control subjects [3-5] and older BD subjects also exhibit worse cognitive performance than younger $\mathrm{BD}$ subjects [6-8]. However, the evidence for these findings are derived primarily from cross-sectional studies; studies examining cognition using longitudinal data are scarce and, among those available, show mixed results. One study found that over a period of up to 3-years, there was no difference in trajectories of cognitive performance in $\mathrm{BD}$ vs. normal controls, but there was greater variability in $\mathrm{BD}$ than the control group for these trajectories [9]. Another study found that there were no group differences between $\mathrm{BD}$ and non-psychiatric comparison participants in the rate of cognitive decline, but $\mathrm{BD}$ who had more lifetime manic episodes showed more precipitous declines [10]. The findings of variability in cog- nitive trajectories in $\mathrm{BD}$ suggests that $\mathrm{BD}$ in itself may not confer to increased risk for cognitive decline. However, it may be possible that there are subgroups of $\mathrm{BD}$ patients with unique risk profiles, such as greater illness chronicity, that show accelerated cognitive decline.

One important risk factor receiving increased attention in recent years is that of sleep disturbances, which is a hallmark symptom of BD. Past studies estimate over 70\% of BD patients experience some sleep disturbance [11]. There is ample evidence to support the hypothesis that sleep disturbance is a risk factor for accelerated cognitive decline in $\mathrm{BD}$. Epidemiological studies in the general population show sleep disturbance to be associated with future cognitive decline [12]. There is also emerging research suggesting a biological link between sleep and dementia pathologystudies of rodents [13] and humans [14,15] show sleep may impart clearance of waste products in the brain built up during the day that may ward against development of dementia biomarkers (e.g., beta-amyloid deposits). There are some cross-sectional studies showing sleep disturbances in $\mathrm{BD}$ to be associated with impairments in domains of cognition, primarily attention and process- 
ing speed [16], but recent reviews have suggested poor sleep may be a factor that drives the poorer cognition seen in $\mathrm{BD}[17,18]$. Given that sleep disturbances are ingrained so profoundly within $\mathrm{BD}$, the high-risk of cognitive impairments in this group, and crosssectional evidence of impairments in cognition in $\mathrm{BD}$, there is a need for more research identifying the potential implications for sleep as a contributor to accelerated cognitive aging in $\mathrm{BD}$ patients.

Future studies that examine sleep and longitudinal cognitive decline in $\mathrm{BD}$ require careful measurement of sleep and cognition over long durations of time. With the growth of wrist actigraphy and consumer wearables (e.g., Fitbits) to measure sleep quality, one can get an accurate representation of sleep over multiple nights and in the usual sleeping environment of their bedroom, which may be hard to assess in a clinical sleep lab. Additionally, careful repeated assessment of cognitive functioning that accounts for any practice effects or are robust to assessing changes over time would also prove useful. New advances in mobile cognitive assessments-instantaneous real-time assessment of cognition via smartphone devices-may be useful in determining the impact of acute cognitive symptoms on long-term cognitive outcomes. Additionally, neuroimaging of brain health through MRI and fMRI may help identify longitudinal change in brain structure that could identify sub-clinical manifestations of cognitive decline in this group.

More research is also needed in understanding the mechanisms for the link between sleep and cognitive aging in BD. Given the unique characteristics of $\mathrm{BD}$ illness, the mechanistic link may be different than that in healthy samples. For example, BD has been shown to be associated with elevated levels of proinflammatory biomarkers, and inflammation is known to be associated with both sleep [19] and cognitive impairments [20]. Other possible mechanisms warranting examination are lifestyle and health behaviors. Better understanding the mechanisms (both biological and behavioral) may advance our ability to intervene at important inflection points in the life course of $\mathrm{BD}$ patients.

In this context, there is also a need for further clinical and intervention research to extend the period of cognitively healthy life in $\mathrm{BD}$. We need more research in the identification of the effective therapies that target sleep-related problems specifically in $\mathrm{BD}$, and in their impact on longitudinal cognitive trajectories. One such therapy, Interpersonal and Social Rhythm Therapy [21], seeks to improve awareness of circadian patterns to help regulate mood fluctuations. Studies examining whether receipt of this and other related therapies protect against accelerated cognitive decline could assist in prevention efforts in this group. We also need more studies using implementation science approaches to evaluate how such therapies work in real-world healthcare systems and determine how to better integrate them in the contexts of mental health clinics. Such efforts would promote rapid dissemination of the therapies that work, and subsequently evaluate the effect on mental healthcare systemwide outcomes.

There remains much to be known about accelerated cognitive decline and the risk factors that may increase this risk in BD. Given the combination of evidence of cognitive decline due to sleep and the high prevalence of sleep disturbance in $\mathrm{BD}$ patients, there is reason to focus on sleep as a potential risk factor. However, it would also be important to examine whether sleep as a risk factor for accelerated cognitive decline in BD may in fact be multivariate- - unique combination of sleep with other factors that increase risk in an additive or multiplicative fashion. Such additional risk factors could be the number of past manic or depressive episodes or other measures of chronicity of illness duration. Filling in the gaps in research discussed here, and adequately addressing these issues in real-world healthcare systems, could result in positive public health outcomes and help promote independence for $\mathrm{BD}$ patients and others with serious mental illness.

\section{Acknowledgments}

Dr. Kaufmann received support from the National Institute on Aging (K01AG061239). Dr. Eyler received support from the National Institute of Mental Health (R01MH103318).

\section{Conflicts of Interest}

The authors have no potential conflicts of interest to disclose.

\section{Author Contributions}

Both Drs. Kaufmann and Eyler contributed to the conceptualization and writing of the manuscript.

\section{ORCID iD}

Christopher N. Kaufmann (1)

https://orcid.org/0000-0002-2946-7857

\section{REFERENCES}

1. Sodhi SK, Linder J, Chenard CA, Miller del D, Haynes WG, Fiedorowicz JG. Evidence for accelerated vascular aging in bipolar disorder. J Psychosom Res 2012;73:175-179.

2. Weiner M, Warren L, Fiedorowicz JG. Cardiovascular morbidity and mortality in bipolar disorder. Ann Clin Psychiatry 2011;23:40-47.

3. Broadhead J, Jacoby R. Mania in old age: a first prospective study. Int J Geriatr Psychiatry 1990;5:215-222.

4. Gildengers AG, Butters MA, Seligman K, McShea M, Miller MD, Mulsant $\mathrm{BH}$, et al. Cognitive functioning in late-life bipolar disorder. Am J Psychiatry 2004;161:736-768.

5. Dhingra U, Rabins PV. Mania in the elderly: a 5-7 year follow-up. J Am Geriatr Soc 1991;39:581-583.

6. Friedman MJ, Culver CM, Ferrell RB. On the safety of long-term treatment with lithium. Am J Psychiatry 1977;134:1123-1126.

7. Savard RJ, Rey AC, Post RM. Halstead-Reitan Category Test in bipolar and unipolar affective disorders. Relationship to age and phase of illness. J Nerv Ment Dis 1980;168:297-304

8. Burt T, Prudic J, Peyser S, Clark J, Sackeim HA. Learning and memory in bipolar and unipolar major depression: effects of aging. Neuropsychiatry Neuropsychol Behav Neurol 2000;13:246-253.

9. Depp CA, Savla GN, Moore DJ, Palmer BW, Stricker JL, Lebowitz BD, et al. Short-term course of neuropsychological abilities in middle-aged and older adults with bipolar disorder. Bipolar Disord 2008;10:684-690.

10. Sánchez-Morla EM, López-Villarreal A, Jiménez-López E, Aparicio AI, Martínez-Vizcaíno V, Roberto RJ, et al. Impact of number of episodes on neurocognitive trajectory in bipolar disorder patients: a 5-year follow-up study. Psychol Med 2019;49:1299-1307.

11. Harvey AG, Talbot LS, Gershon A. Sleep disturbance in bipolar disorder across the lifespan. Clin Psychol (New York) 2009;16:256-277. 
12. Spira AP, Chen-Edinboro LP, Wu MN, Yaffe K. Impact of sleep on the risk of cognitive decline and dementia. Curr Opin Psychiatry 2014;27:478-483.

13. Xie L, Kang H, Xu Q, Chen MJ, Liao Y, Thiyagarajan M, et al. Sleep drives metabolite clearance from the adult brain. Science 2013;342:373-377.

14. Shokri-Kojori E, Wang GJ, Wiers CE, Demiral SB, Guo M, Kim SW, et al. $\beta$-Amyloid accumulation in the human brain after one night of sleep deprivation. Proc Natl Acad Sci U S A 2018;115:4483-4488.

15. Spira AP, Gamaldo AA, An Y, Wu MN, Simonsick EM, Bilgel M, et al. Self-reported sleep and $\beta$-amyloid deposition in community-dwelling older adults. JAMA Neurol 2013;70:1537-1543.

16. Bradley AJ, Anderson KN, Gallagher P, McAllister-Williams RH. The association between sleep and cognitive abnormalities in bipolar disorder. Psychol Med 2019 Jan 16 [Epub]. https://doi.org/10.1017/S0033291718004038.

17. Boland EM, Alloy LB. Sleep disturbance and cognitive deficits in bipolar disorder: toward an integrated examination of disorder maintenance and func- tional impairment. Clin Psychol Rev 2013;33:33-44

18. McKenna BS, Eyler LT. Overlapping prefrontal systems involved in cognitive and emotional processing in euthymic bipolar disorder and following sleep deprivation: a review of functional neuroimaging studies. Clin Psychol Rev 2012;32:650-663.

19. Irwin MR, Olmstead R, Carroll JE. Sleep disturbance, sleep duration, and inflammation: a systematic review and meta-analysis of cohort studies and experimental sleep deprivation. Biol Psychiatry 2016;80:40-52.

20. Berk M, Kapczinski F, Andreazza AC, Dean OM, Giorlando F, Maes M, et al. Pathways underlying neuroprogression in bipolar disorder: focus on inflammation, oxidative stress and neurotrophic factors. Neurosci Biobehav Rev 2011;35:804-817.

21. Haynes PL, Gengler D, Kelly M. Social rhythm therapies for mood disorders: an update. Curr Psychiatry Rep 2016;18:75. 